\title{
Rakshak - A Bore Well Rescue Bot
}

\author{
${ }^{1}$ Ashwini.S, ${ }^{2}$ Bhagya Shree S J, ${ }^{3}$ Jeevitha Kalaashilpa N C, ${ }^{4}$ Kadri Srinidhi rao, ${ }^{5}$ Dr. P. N. Sudha \\ ${ }^{5}$ Professor and Head of department, Electronics and Communication department, K S Institute of \\ Technology, Bangalore, India, ${ }^{1}$ ashwiniselvaraj003@gmail.com, ${ }^{2}$ bhagi.sj22@ gmail.com, \\ 3jeevitha1998nc@gmail.com, ${ }^{4}$ nidhivadi234@gmail.com, ${ }^{5}$ pnsudha@ksit.edu.in
}

Abstract- Over the past few years, there have been several accidents of children falling into abandoned bore wells in India. Abandoned bore wells have turned into death pits for kids. This problem is found all over India. Rescue teams spend hours and sometimes days in futile attempts to save these kids. A lot of money is being spent in these missions. In most cases they are unable to save the kids. Such events have happened umpteen numbers of times in the past, and every time either the government of the bureaucracy are being blamed. The rescue process of saving the child from bore well is a long and complicated procedure $\&$ to approach the victim parallely takes about 20-60 hours. This complicated process makes $70 \%$ of the rescue operations to fail. Very few of the victims have been saved in such accidents. This paper briefs different techniques used to save kids fallen into the abounded bore wells and also briefly discuss the drawbacks in these methods. In this paper we propose a technique to deals extreme Safe handling of the victim with cent percent recusal \& further eradicating the kid from falling in bore well. Our Bot designed constitutes a best Ergonomic Design and performs safest rescue operation.

Keywords- bureaucracy, eradicating, ergonomic, futile, umpteen, victim

\section{INTRODUCTION}

Water scarcity is the major problem faced by the human society. Due to drought and depletion of underground water more bore wells are dugged on the surface of the earth. Due to water scarcity more bore wells are being sunk .In many areas the bore wells are dugged and left open without any proper covering. This abandoned bore wells have become death traps and started taking many innocent lives of small children. Now a days falling of children in bore wells are increasing due to the carelessness and playful activities of the children. The holes dugged for the bore wells are deep and around 700 feet. In these cases the rescue of children from such deepest bore wells is quite challenging. Many times the rescue system for children fallen in the bore wells may risk the child life. As the famous saying of famous scientist Benjamin Franklin "An Ounce of Prevention is worth a Pound of Cure". In order to overcome these hurdles a new system of preventing children from falling into bore wells is designed wherein the sensors will be placed at the top of the bore well pipeline which helps to sense the human being if he/she falls in the pipeline and data is sent to controller[3].The robot is put into the well and is moved accordingly to analyze the rescue position furthermore the anchorage set has fixed the robot and the stretching arm has stretched out till to the underside of the victim and the supporting bracket is applied to perform rescue operation [1].

\section{PROPOSED METHODOLOGY}

The idea for this proposed system is conceived by witnessing the rapid bore well accidents prevailed in India during 2010-19 to prevent the children fall into unclosed bore well \& rescue the victim by avoiding the technical and financial risks involved in rescue operation and to perform the rescue operation in the extreme conditions. The basic concept of this project is to bring the victim to ground within short span of time. This could be achieved using the advanced ergonomic design present in the robot. It seeks to please the functionality of tasks with the requirements. Ergonomic design focuses on the compatibility of the objects and environments with the humans using those platforms. For completion of present design $\&$ to reach prototype stage, the following steps are followed as shown in the flow charts - 
Design needs, Objective, Problem Definition, Concept Design, Preliminary Design Detailed Design, Design Communication and Final design. The main aim of the project is to make safe and sophisticated rescue bots. After making the concept ready, further design and modeling is carried out.

Design criteria to design rescue bots for saving the kids trapped in bore wells, following three criteria are considered: I)supplying oxygen to the victim trapped inside the bore well II)picking him/her up safely from the bore well without failure or dropping of the robotic arm in between. III)Taking out the victim safely as early as possible. Considering the above criteria rescue bot is being designed. The reason that these rescue robots are not into market or common use is that they fail to serve one or all of the above. Hence every aspect of design is being taken care to make sure that our design satisfies above mentioned criteria to the best extent. The bot is expected to be fabricated in a way that the trained operator opens the stand and fixes over the bore well and gives the input regarding depth and diameter of the bore well. The bot self- operating system starts with the given input regarding depth well. The IR sensor placed along with camera on the bottom will detect the distance of the victim from the ground. Fresh air is provided through a special pipe arranged from the rescue robot. With the detection of the victim all the conditions of the victim is calculated \& the best way to rescue is detected \& is being rescued with the safety balloon procedure.

\section{BLOCK DIAGRAM ANDFLOW CHART}

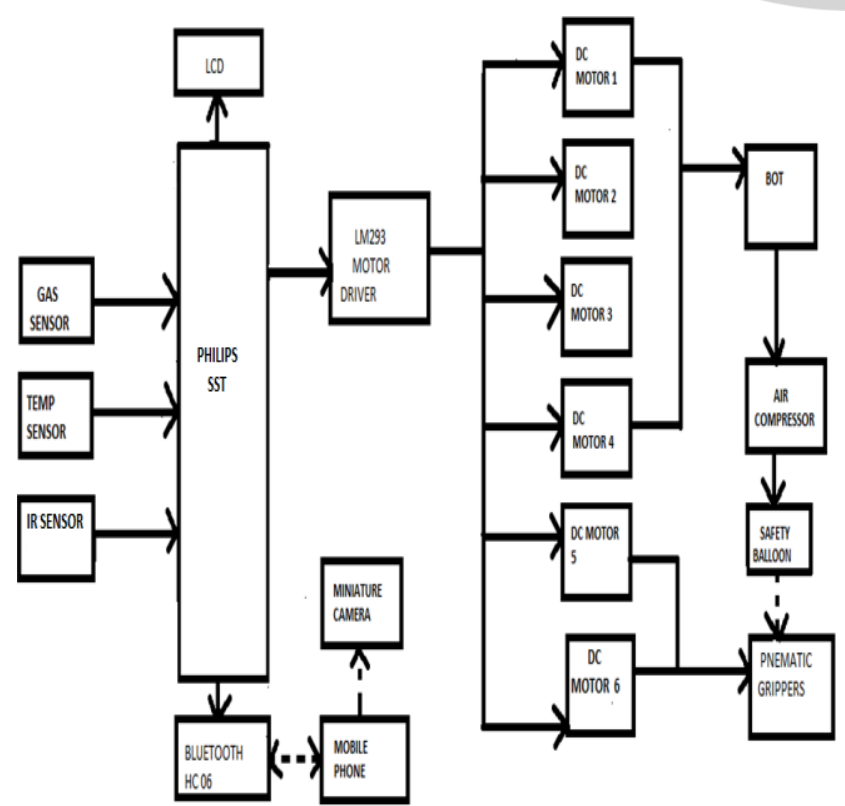

Fig 1.1: Block Diagram of bore well rescue bot

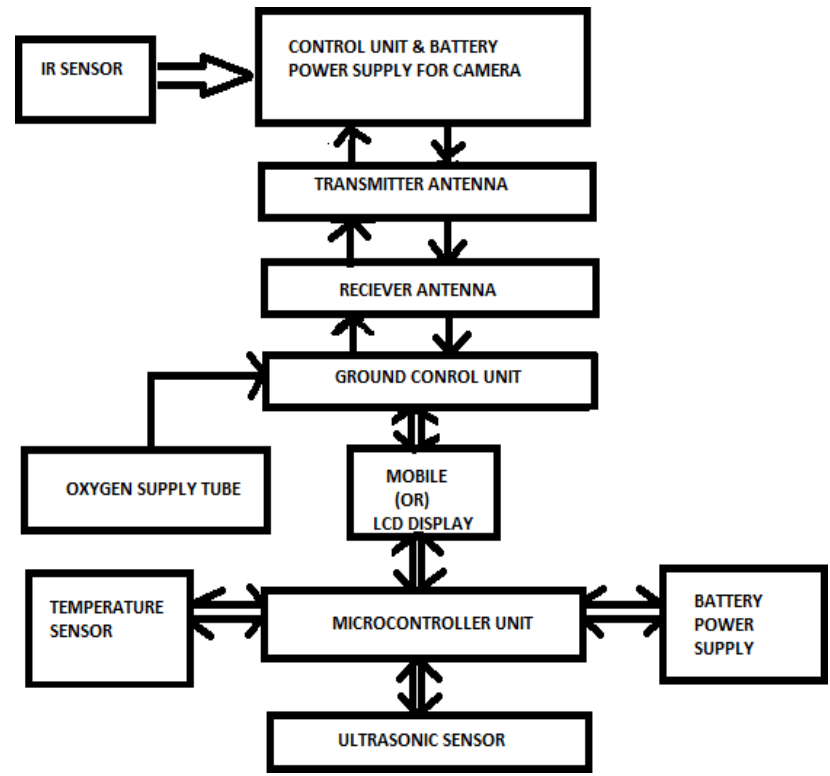

Fig1.2: Flowchart of Working of bore well rescue bot

\section{RESULTS}

A low cost Bore well Robot with extra ordinary feature is designed and manufactured as shown in figures (Fig 4.1 to 4.3). The movement of the robot is controlled using Android app and also the output of the all the sensors is displayed on the Led screen.

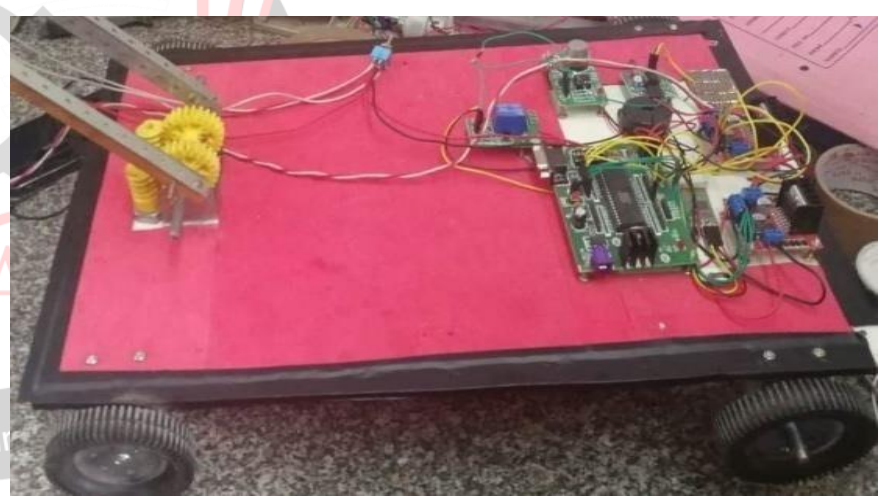

Fig 4.1: Top view of the bore well bot

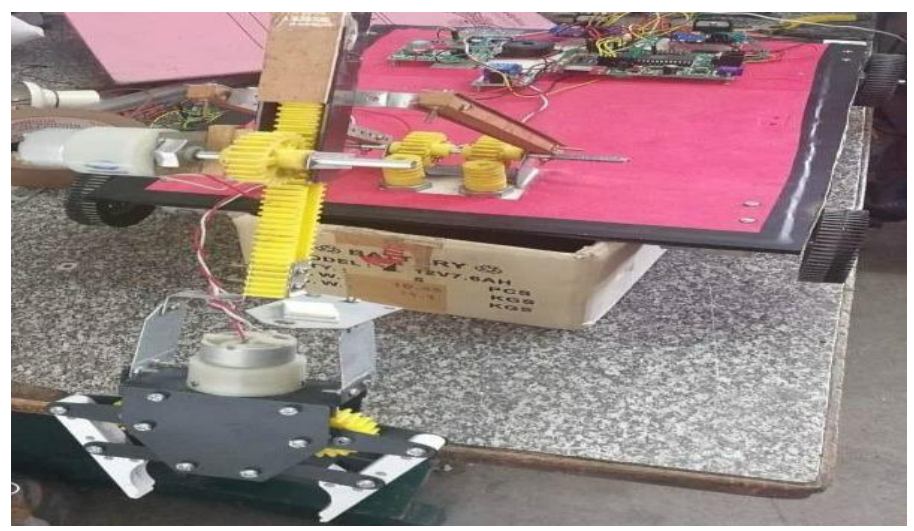

Fig 4.2: Front view of the bore well bot 


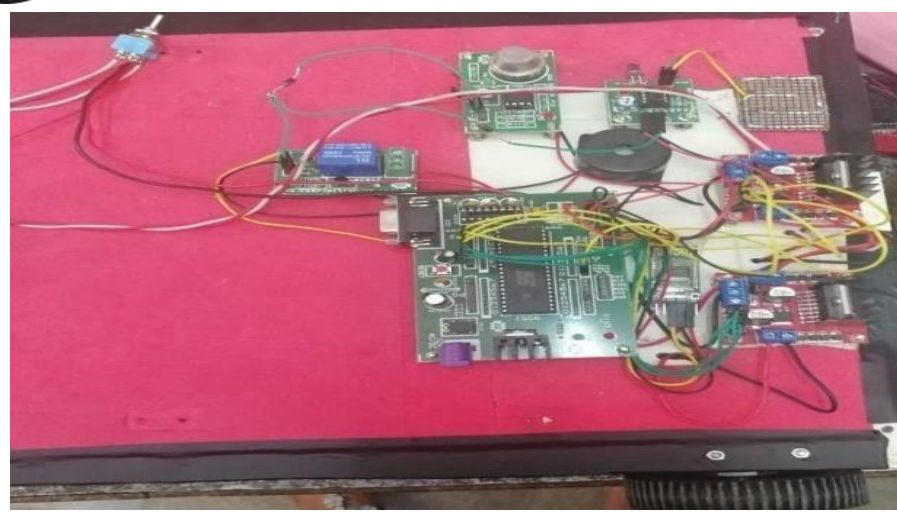

Fig4.3:Electrical connections of the bore well bot

\section{CONCLUSION AND FUTURESCOPE}

Human life is very precious and our proposed system Bore well child server is a significant attempt to save the life of the victim of bore well accidents. Besides this, it has a unique capability of climbing through vertical and inclined pipes makes wide scope of application for this machine in manufacturing industries and other relevant fields. In the current design of Bore well child saver machine has been made to suit every possible situation that may occur during rescuing operation. This structure is made strong enough to sustain all possible loads though it is made flexible at the same time to adjust wider range of bore diameter and any change in the diameter of bore. In rescuing operation time is a vital factor which alone can determine the success or failure of the whole operation. Thus, it has been designed keeping the entire consequences in mind that may arise during the operation. We like to conclude with the help of our research project that we will be able to rescue the child safely.

The extended aim of the project is to ensure the child from falling in to the bore well by creating smart cap system. This enables safety measures around the bore well $\&$ eradicates the victim from falling with advanced technical \& service based support system.

\section{ACKNOWLEGDEMENT}

We would like to thank our guide Dr. P. N. Sudha, HOD of Electronics and Communication Department, for her valuable guidance as well as her suggestions for creating this paper on RAKSHAK-BOREWELL RESCUE BOT. This work was carried out at $\mathrm{K} S$ Institute of Technology..

\section{REFERENCES}

[1] Wang Chuanjiang ,Sun Xiujuan , Zhang Zhixian\&Zou Jixiang virtual Prototype
Realization and simulation for Small- Caliber Deep Well Rescue Robot, 2011 Third International Conference on Measuring Technology and Mechatronics

Automation

https://ieeexplore.ieee.org/document/572168/.

[2] Nish Mohith Kurukuti ,Mahesh Jinkala, Purushotham Tanjeri, Somasekhar Reddy Dantla and Mallikarjuna Korrapati, A Novel Design of Robotic System for Rescue in Bore well Accidents, 2016 International Conference on Robotics and Automation for Humanitarian Applications (RAHA) detection," 2011 IEEE International Conference on Computer Science and Automation Engineering, Shanghai, pp. 300-304,2011.

[3] Kavianand G, Gowri Ganesh K \& KarthikeyanP in Smart Child Rescue System from Borewell https://ieeexplore.ieee.org/document/76 03056/

[4] Arthika, S.Chidammbara Eswari and R.Prathipaand D.Devasena, Borewell Child Fall Safeguarding Robot, International Conference on Communication and Signal Processing, April3-52018,India. https://ieeexplore.ieee.org/document/852 4550/6

[5] Aashvij Shenai, Abhijeet Antin ,Pallvai R,Dawnee Soman . Development of In-Pipe Robot for Assistin gBorewell Rescue Operations, 2018, IEEE Third InternationalConference onCircuits, Control,Communication and Computing https://ieeexplore.ieee.org/document/572 1687/

[6] Raj Manish, P. Chakraborty , G. C. Nandi, Rescue systematics in bore well Environment, Cornell university library.

[7] Palwinder Kaur ,Ravinder Kaur, Gurpreet Singh Pipeline Inspection and Bore well Rescue System IEEE,VOL3,NO.

[8] K. Saran , S. Vignesh , Marlon Jones Louis Bore well Rescue System International Journal of Research aeronautical VOL1, Issue 4, pg 61-80

[9] B.Bharathi, B.Suchita Samuel Design and Construction of Rescue System ,International Journel of Scientific Engineering and Research [IJSER] Volume 1Issue

[10] John Jose Pottery ,System for borewell Rescue anal jothi college of engineering.

[11] Standard operating procedure on borewells incident response. https://www.ndrf.gov.in

[12] Ashwini.S ,Bhagya Shree S J , Jeevitha Kalaashilpa N C, Kadri Srinidhi Rao, "RAKSHAK-Bore well Rescue Bot," survey paper, Department of Electronics \&Communication Engineering, KSIT, IJLEMR,2020. 